\title{
Community completeness as a measure of restoration success: multiple-study comparisons across ecosystems and ecological groups
}

\author{
Norbertas Noreika $^{1,2}$ (D) Meelis Pärtel $^{3} \cdot$ Erik Öckinger $^{1}$
}

Received: 21 May 2020/Revised: 18 August 2020 / Accepted: 9 September 2020 /

Published online: 17 September 2020

(C) The Author(s) 2020

\begin{abstract}
When restoring habitat for biodiversity, the most effective outcome will be achieved by restoration projects which target several organism groups or ecosystem types. Such integrated approaches require direct comparisons among different ecological communities while evaluating success of restoration. The Community Completeness Index (CCI) is a recently developed metric that allows such comparisons by accounting for both present and absent but otherwise suitable taxa. We empirically evaluated the applicability of CCI for assessing the outcome of ecological restoration. We analyzed how species richness and the completeness of ecological communities recover after restoration, for different ecological groups and ecosystem types, and how it develops over time after restoration. Analyses were performed on 18 datasets with per site presence-absence data from Northern Europe. Each dataset represented one of the three habitat types (mire, forest, grassland) and different ecological groups (plants, flying insects, epigeic invertebrates). Datasets contained pristine, degraded and restored sites. We calculated the dark diversity and subsequently CCI based on species co-occurrences. Our multiple-study analyses revealed that CCI of grassland plant communities increased faster after restoration than invertebrate communities or plant communities in forests and mires. In addition, flying insect communities demonstrated significantly highest CCI in pristine mires. Some results were significant only for richness but not for CCI indicating species pool effect. Finally, completeness and species richness of restored communities increased with time since restoration. As such, our study demonstrated that CCI is a useful tool in evaluating restoration success across different organism groups and ecosystem types.
\end{abstract}

Keywords Dark diversity · Habitat restoration - Species co-occurrences · Species pool $\cdot$ Species richness $\cdot$ Time lag

Communicated by Louise Amy Ashton.

Norbertas Noreika

norbertas.noreika@gmail.com

Extended author information available on the last page of the article 


\section{Introduction}

The Anthropocene is characterized by rapid human-caused ecosystem loss and degradation (Lewis and Maslin 2015; Ellis 2018). To meet international targets on halting biodiversity loss, the importance of ecological restoration is widely emphasized (Suding 2011). In order to reveal if restoration targets are met, restoration actions require evaluations of their success, which is overall a key subject for the development of restoration ecology (Suding 2011). Nevertheless, how to evaluate restoration success is highly debatable (see e.g., Hobbs et al. 2009; McAlpine et al. 2016). The traditional use of past and present ecosystems as targets in restoration projects can be inappropriate due to rapid and uncertain environmental change (Corlett 2016). Furthermore, evaluations of restoration actions should optimally use Before-After-Control-Impact (BACI) study design and long term post-restoration monitoring (Christie et al. 2019). Due to high costs, these are rarely done. Therefore, success evaluation methods reflecting the resilience of restored ecosystem to future changes should be considered (Suding 2011; Corlett 2016).

It has been suggested that more effective outcomes of restoration for biodiversity should be achieved via integrated plant-animal (i.e., targeting several taxa) restoration approaches (McAlpine et al. 2016), and when whole landscapes are being restored (e.g., rewilding, Corlett 2016). Both approaches require comparisons across separate ecological communities while evaluating restoration success, either within the same ecosystem (across taxa comparisons) or within the same landscape (across habitat comparison of some representative taxa), respectively. Across taxa comparisons within focal ecosystem would show if the entire ecosystem is restored, not just its separate elements (Pärtel et al. 2013). In order to compare restoration success across taxa, standardised metrics that can easily be compared between taxa are needed.

Usually, traditional diversity measures (e.g., species richness) are limited in possibilities to perform direct comparisons across communities in different locations, as there is a variation in the size of the species pool. The habitat-specific species pool is defined as the set of species which potentially can inhabit a site (Zobel 2016). Community completeness (Pärtel et al. 2013) can be used for direct comparisons, as it standardizes local richness to available species pool. The community completeness is describing the proportion of habitat-specific species pool which is present in the site, i.e. explores local diversity which is mathematically independent of species pool size. The rationale behind using community completeness for assessing restoration success is that the aim of any restoration effort is to achieve a biological community that contains as high proportion of the habitat-specific species pool as possible. The species pool for a given site includes two species diversity measures: observed diversity (habitat-specific species actually present in a site) and dark diversity (the absent portion of habitat-specific species pool (Pärtel et al. 2011)). While calculation of observed diversity is straightforward, dark diversity cannot be measured directly and can only be estimated, e.g. from species co-occurrence patterns (Lewis et al. 2016). These two measures can be used to calculate the relatively recently proposed Community Completeness Index (CCI), expressed as $\ln$ (observed diversity/dark diversity) (Pärtel et al. 2013; Lewis et al. 2016). CCI indicates whether the focal community is becoming more (higher $\mathrm{CCI}$ ) or less (lower $\mathrm{CCI}$ ) complete following restoration activities. As a relative measure, $\mathrm{CCI}$ is comparable among different communities. If restoration is successful, we might expect communities to become more complete with time, thus revealing higher ecosystem or landscape resilience. However, this remains to be evaluated empirically. 
The properties of the CCI suggests that it could be used in formulating clear goals of most ecological restoration projects and refer restoration targets to the mechanisms of larger processes (Török and Helm 2017), but it was not tested empirically. Restoration projects should aim to achieve higher CCI by encouraging all habitat-specific species available from the regional species pool to disperse and remain in the communities after restoration actions have been implemented. Thus, changes in CCI reflect whether desirable and available species are colonizing restored sites. In contrast, traditional diversity measures such as richness do not consider species identity and thus do not necessarily reveal if habitat was really improved for the target habitat-specialist species. For example, higher richness could be achieved merely by influx of generalist and invasive species, as well as specialists. Post-restoration community completeness should depend on spatial and temporal constraints, i.e. site connectivity and species dispersal abilities, and the time since restoration. Indeed, plant and hoverfly species with poor dispersal abilities tend to be part of the dark diversity more often than good dispersers (Riibak et al. 2015; Moeslund et al. 2017; Miličić et al. 2020). Further, communities should become more complete with increasing time since restoration actions, as potentially more species should continuously arrive into the restored sites under successful restoration (e.g. "Field of Dreams" hypothesis, Palmer et al. 1997). Longer time should be required to reach higher postrestoration completeness values for the communities dominated by poor dispersing species than those formed mostly of good dispersers. The possibility to restore an ecosystem might also depend on to what extent species are adapted to disturbances. Recovery from major disturbance should be easier for ecosystems which experience continuous but low intensity disturbances than for those rarely but intensively or almost never disturbed (see e.g., Betts et al. 2019). Finally, communities of different trophic levels could recover based on their trophic position in the food web, thus reflecting the sequence of species arrival after restoration: carnivores are dependent on herbivores, while herbivores are dependent on autotrophs (Lindeman 1942).

The aims of our study were to (a) evaluate the applicability of the CCI for assessing the outcome of restoration actions, and (b) evaluate how the completeness of ecological communities recovers after restoration, for different ecological groups and ecosystem types and how CCI recovery differs from the recovery of species richness. We hypothesize that:

(1) Species richness will show similar but non-identical patterns of responses to restoration in comparison to CCI (due to the lack of standardization to local species pool size). (2) Restoration increases community completeness, such that CCI values are greater for restored than degraded communities and pristine communities are expected to have the highest completeness, and that community completeness in restored sites increases with time since restoration. (3) Across ecosystem comparisons should show that communities dominated by better dispersers and experiencing frequent, but low intensity disturbance (semi-natural grasslands), have higher completeness after restoration than those dominated by poor dispersers and affected rarely by severe disturbance (forests) and the lowest completeness should be seen for those almost never disturbed communities (mires). (4) For across ecological group comparisons, we formulate two different hypotheses for the completeness of investigated groups, depending on whether mobility or trophic position is more important: (i) if mobility is more important, we would expect that CCI values from highest to lowest would follow the order: flying insects, epigeic insects and plants; (ii) if trophic level is more important, we would expect CCI to be ordered from highest to lowest as plants, herbivores and predators. 


\section{Materials and methods}

\section{Data}

On November 2018 we searched for ecological restoration studies from the region of Northern Europe by entering different combinations of three keywords into Google Scholar search field: restor* AND habitat type [= grassland, meadow, forest, woodland, mire, bog] AND country [= Finland, Sweden, Norway, Denmark, Netherlands, Belgium, Estonia, Latvia, Lithuania]. We only searched for studies published in 2004 or later. The reason was both that we considered possible differences in ecological conditions due to global climate change among studies over a longer period, and that we expected it to be difficult to get access the full data for studies older than $\sim 15$ years. We restricted our search to the northern part of Europe (Nordic-Baltic countries and Benelux), since this region would share similar climatic conditions and biogeographical history, thus resulting in similar habitat-specific species pools. After the search we selected publications which included ecological restoration datasets with such minimal requirements: species presence-absence data of plants, insects or spiders, one of three habitat types (semi-natural grasslands, mires, forests), three (pristine, restored, degraded) or two (pristine and restored, or degraded and restored) treatments, at least 20 total replications in a study system (= sites or sites*treatment), and data on time since restoration, i.e. the time between restoration action were performed and the time of the evaluation, in years (if available). We contacted authors asking them to provide species presence-absence data per site, applied treatment for each site and indication of time since restoration for restored sites. This resulted in 18 datasets with per site data from four countries (Table 1). 16 datasets contained data of time since restoration in years for restored sites. We organized all datasets so that each site would represent one of the three treatments (space-for-time substitution): pristine, degraded and restored. Most of the datasets included all three treatments, but some had only either pristine and restored or degraded and restored treatments. One paper (Marozas et al. 2007) did not frame the study in a restoration context, but compared burned and unburned managed forest sites. As burning is a common practice in forest biodiversity restoration projects (see e.g. Kärvemo et al. 2017), we considered this a restoration treatment and included these data into our restoration analyses.

Datasets were grouped for comparison across ecosystems and across ecological organism groups. We grouped the data sets on plant communities into three ecosystem types which reflects different intensity and regularity of disturbances and thus the respective communities are dominated by good or poor dispersing species: (1) semi-natural grasslands (frequent low intensity disturbance, good dispersing plants), (2) forests (rare high intensity disturbance, poor dispersing plants), (3) mires (no regular disturbance, poor dispersing plants). The same grouping was also done for flying insects, but it covered only two ecosystem types: grasslands and mires. For ecological group comparisons we grouped our datasets within grasslands and mires separately based on organism movement and dispersal abilities: (1) flying insects (highly mobile, good dispersers; it included bees, hoverflies, craneflies, lepidopterans), (2) epigeic invertebrates (intermediate dispersal abilities; incl. ants, carabid beetles, spiders), (3) plants (sessile organisms, limited dispersal abilities; incl. vascular plants, bryophytes). We are aware that such grouping might be oversimplistic from the perspective of individual species (as e.g. the seeds of some plant species can be carried long distances by wind), but here we consider the dominant mode of 


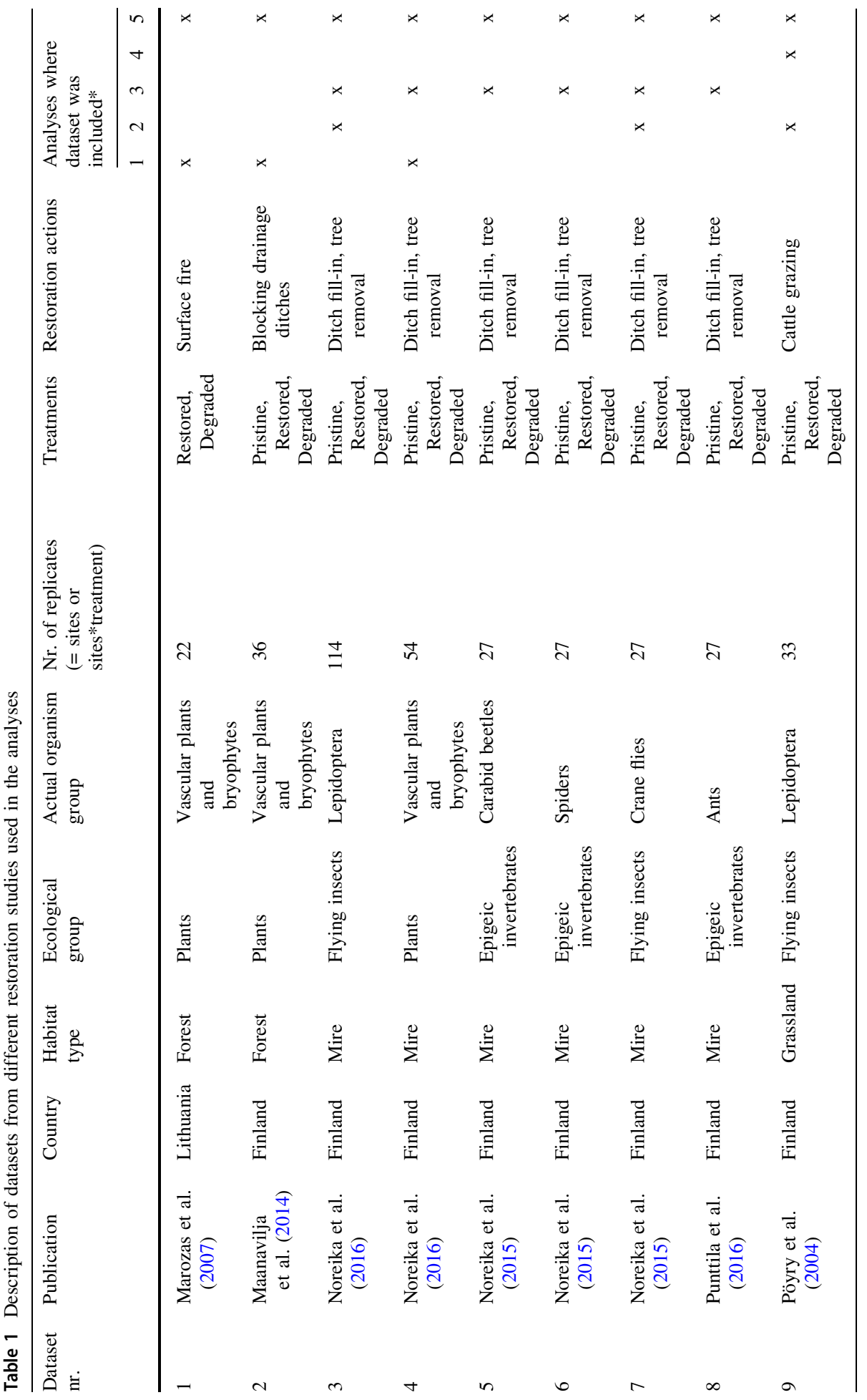




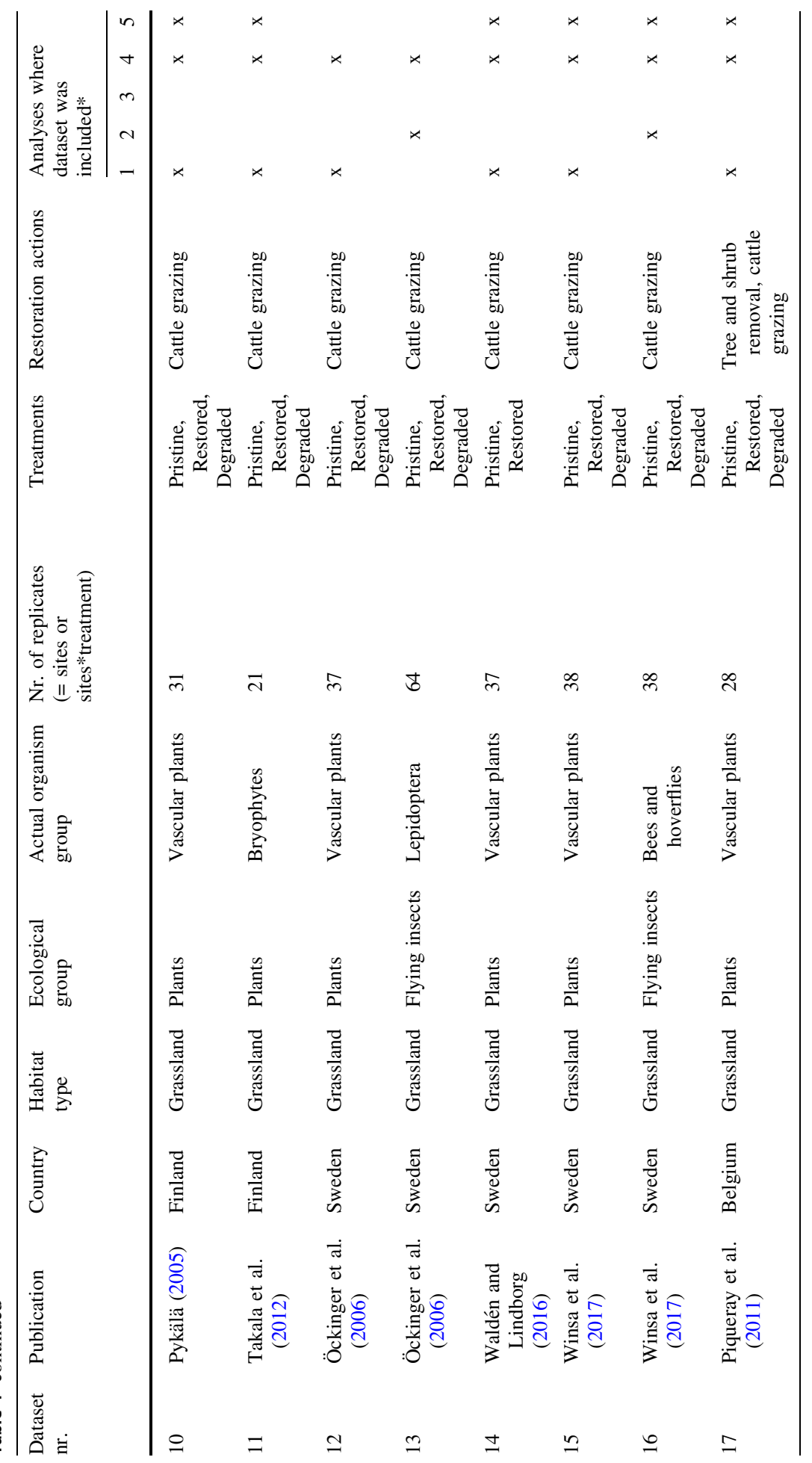




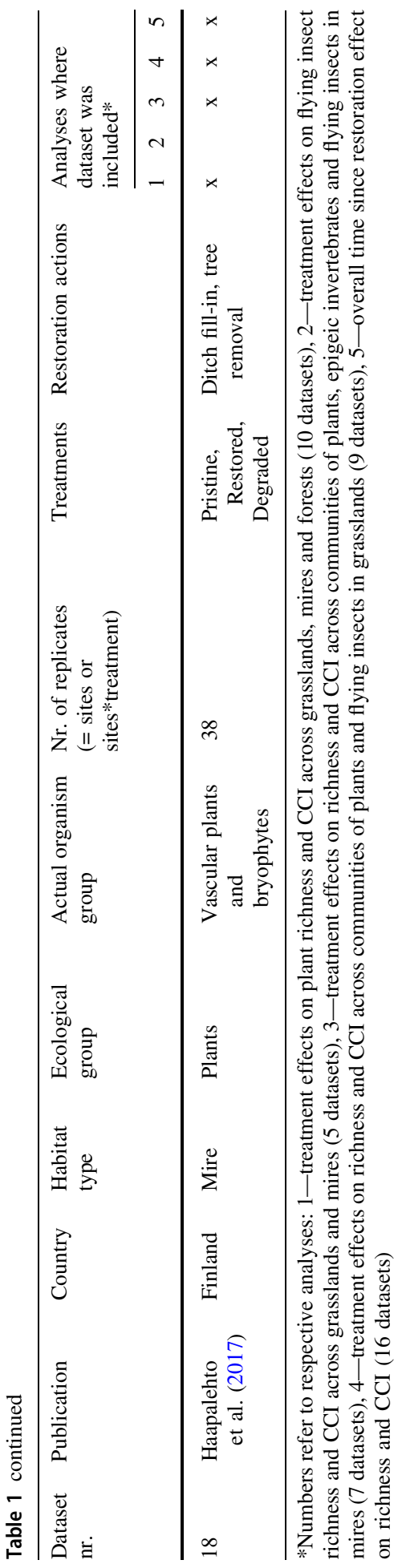


dispersal of most species forming specific assemblage and assume that active behaviordriven animal dispersal is more effective than passive plant dispersal from habitat restoration perspective. At least partly, the same grouping could be seen from trophic level perspective: autotrophs or producers (= plants), primary consumers (= flying insects; majority of species, but not necessarily all as, e.g., some hoverflies are predators in larval stage), secondary consumers (= epigeic invertebrates; again, appropriate for most of the species, but some are herbivores, e.g. some carabid beetle species).

\section{Calculations of dark diversity, completeness and species richness}

From the data provided by the authors, we calculated habitat-specific species pools and dark diversity for each site within each dataset by employing the co-occurrence method proposed by Lewis et al. (2016) and available online at https://shiny.botany.ut.ee/DarkDiv/ . The general idea of the method is that present species are used as indicators for all absent species (targets): those absent species which elsewhere likely co-occur with many present species are selected to the dark diversity. Calculations are based on Beals index which determines the proportion of indicator species frequency where it co-occurs together with the target species (ratio ranging between 0 and 1). For each target species these proportions are averaged over all indicator species present in the community. The Beals index depends mathematically on the frequency of target species (common species have higher values) and therefore species specific thresholds are used. For the thresholds we calculated Beals index for all species across all sites. The threshold for a species is determined from the Beals index values at sites where the species is actually present by selecting a typical low value needed to have the species present. We used a narrow definition of dark diversity which includes fewer species but with more confidence (i.e. the 10th percentile of the index found in the sites where the species was actually present; the broad definition uses the 1st percentile).

In order to include as much co-occurrence information as possible, we used the sites of all treatments within each dataset for determining co-occurrences. As such, dark diversity was determined by a statistical technique, rather than relying on subjective decisions on whether species should belong to particular habitat-specific species pool or not.

We calculated community completeness for each site within each dataset as follows: Completeness $=\ln$ (observed diversity/dark diversity). Such log-ratio serves as a logistic transformation of percentages or proportions. Therefore, it is not bounded between 0 and $100 \%$ (or 0 and 1) and could be used in statistics that expect unlimited sample space (e.g., mean calculations, models). If site's dark diversity was equal to zero, we assigned 0.5 value instead to make completeness calculations possible.

As a measure of species richness, we used the observed number of species per site. Species richness was log-transformed before the analyses to keep it on the same scale as completeness.

\section{Statistical analyses}

In order to evaluate restoration treatment and time since restoration effects on community completeness and species richness, we ran linear-mixed models (lme function from package nlme (Pinheiro et al. 2020)) in R version 3.6 (R Core Team 2019). Schematic overview of all performed analyses is given in Fig. 1. Two alternative response variables 


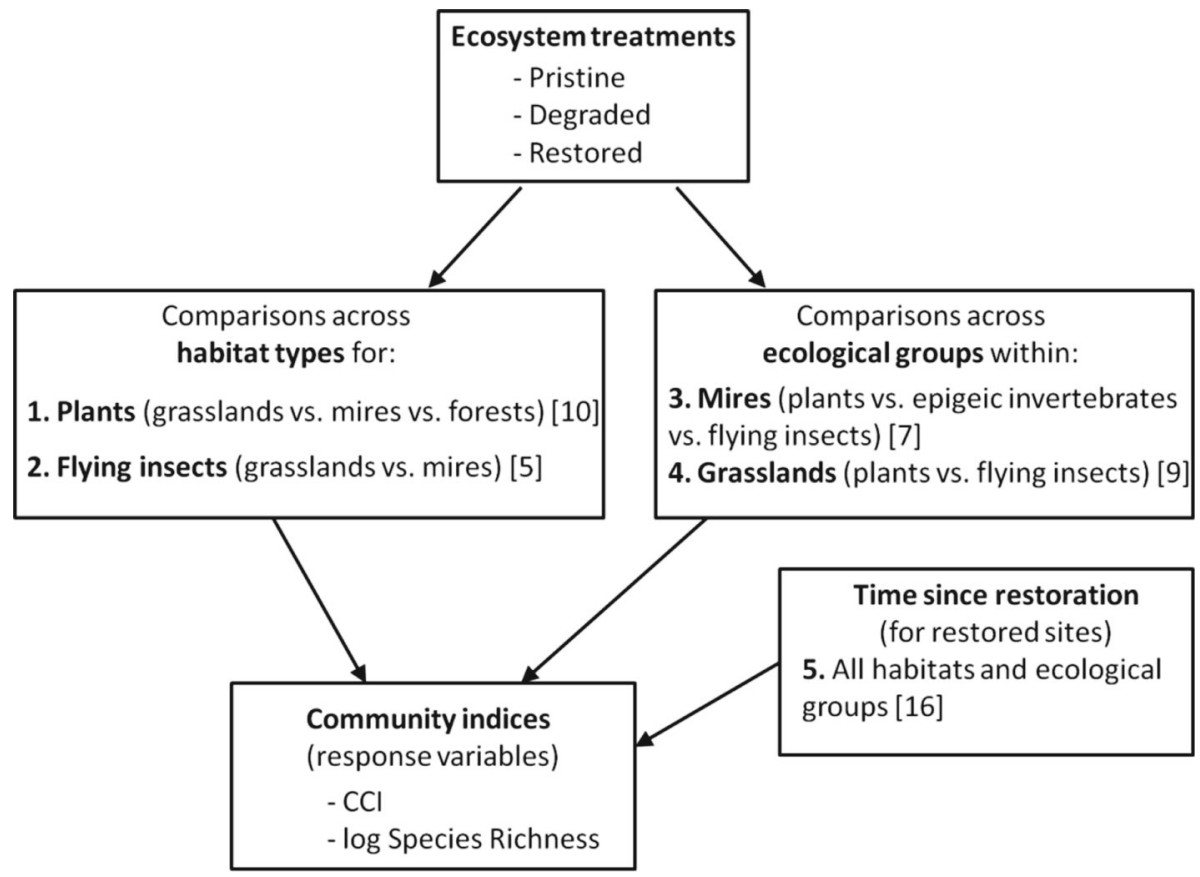

Fig. 1 Schematic overview of performed analyses. Ecosystem treatment and time since restoration (for restored sites) effects on community indices (CCI and Species Richness) were evaluated by employing linear-mixed models. Separate analyses are numbered (1-5) and corresponds to the numbers of analyses in Table 1. The number of datasets used for each separate analysis is written in square brackets

were community completeness and log-species richness. Sites nested within each dataset were included as a random effect.

The treatment analyses were performed by making comparisons across habitats (for separate ecological groups) and across ecological groups (within separate habitat types). Treatment effect models contained three treatments (pristine, restored, degraded) and treatment interaction with ecosystem type (in across ecosystem comparisons) or ecological group (in across ecological group comparisons). At least two datasets for specific category (ecosystem type or ecological group) were required to include it in the respective analyses.

Models testing the effect of time since restoration on community completeness and species richness included only restored site data from the respective datasets. In these models, the actual number of years between the restoration and biodiversity survey served as an explanatory variable (one year per site). These analyses were performed at two levels: (1) Overall time since restoration effect on completeness and species richness of communities. Here 16 datasets were included with completeness and species richness as alternative response variables and time since restoration as an explanatory variable. There was no data grouping by ecological groups or habitat types. (2) Time since restoration effect on community completeness and species richness of ecological groups within particular habitat type (models with time since restoration*ecological group interaction) and on CCI and richness of plant communities across habitat types (models with time since 
restoration*habitat type interaction). These analyses aimed to reveal if time since restoration effect depends on ecological group or habitat type.

\section{Results}

\section{Treatment effects on species richness and community completeness of different habitat types}

We had enough replicates (= datasets) per habitat type to perform analyses on treatment effects across habitat types on species richness and CCI of plants and flying insects (Table 2; Fig. 2).

Treatment effects on plant species richness and community completeness across grasslands, mires and forests (10 datasets, Table 1). Plant species richness was highest in pristine and restored grasslands in comparison to any other differently treated habitat type, demonstrated by two significant interactions: pristine* grassland (overall highest richness) and restored*grassland (Table 2; Fig. 2a). Similarly, the completeness was highest for plants in restored grasslands, with lower levels of completeness in restored forests and mires, and in degraded sites of all three habitat types (Fig. 2b), indicated by a positive restored*grassland interaction (Table 2 ).

Treatment effects on flying insect species richness and community completeness across grasslands and mires (5 datasets, Table 1). Flying insect species richness were significantly lower in mires than in grasslands (Table 2; Fig. 2c). Moreover, two interactions were positively significant: pristine*mire and restored*mire, indicating highest flying insect species richness in pristine sites and positive restoration effect on it. Only the interaction pristine*mire were significantly positive for community completeness of flying insects (Table 2; Fig. 2d).

\section{Treatment effects on species richness and community completeness of different ecological groups}

We had enough replicates (= datasets) per ecological group to perform analyses on treatment effects across ecological groups within mires and grasslands (Table 3; Fig. 3).

Treatment effects on species richness and community completeness across communities of plants, epigeic invertebrates and flying insects in mires (7 datasets, Table 1). Species richness across ecological groups in mires showed several significant effects (Table 3; Fig. 3a). Pristine mire communities were associated with significantly lower species richness. However, both plant and flying insect richness was significantly positively associated with pristine sites (significant Pristine*Flying insects and Pristine*Plants interactions). Moreover, flying insect richness in mires were positively affected by restoration (significant Restored*Flying insects interaction). In terms of community completeness across ecological groups in mires, only interaction Pristine*Flying insects were nearly significant and positive (Fig. $3 b$ ).

Treatment effects on species richness and community completeness across communities of plants and flying insects in grasslands (9 datasets, Table 1). Grassland plant species 


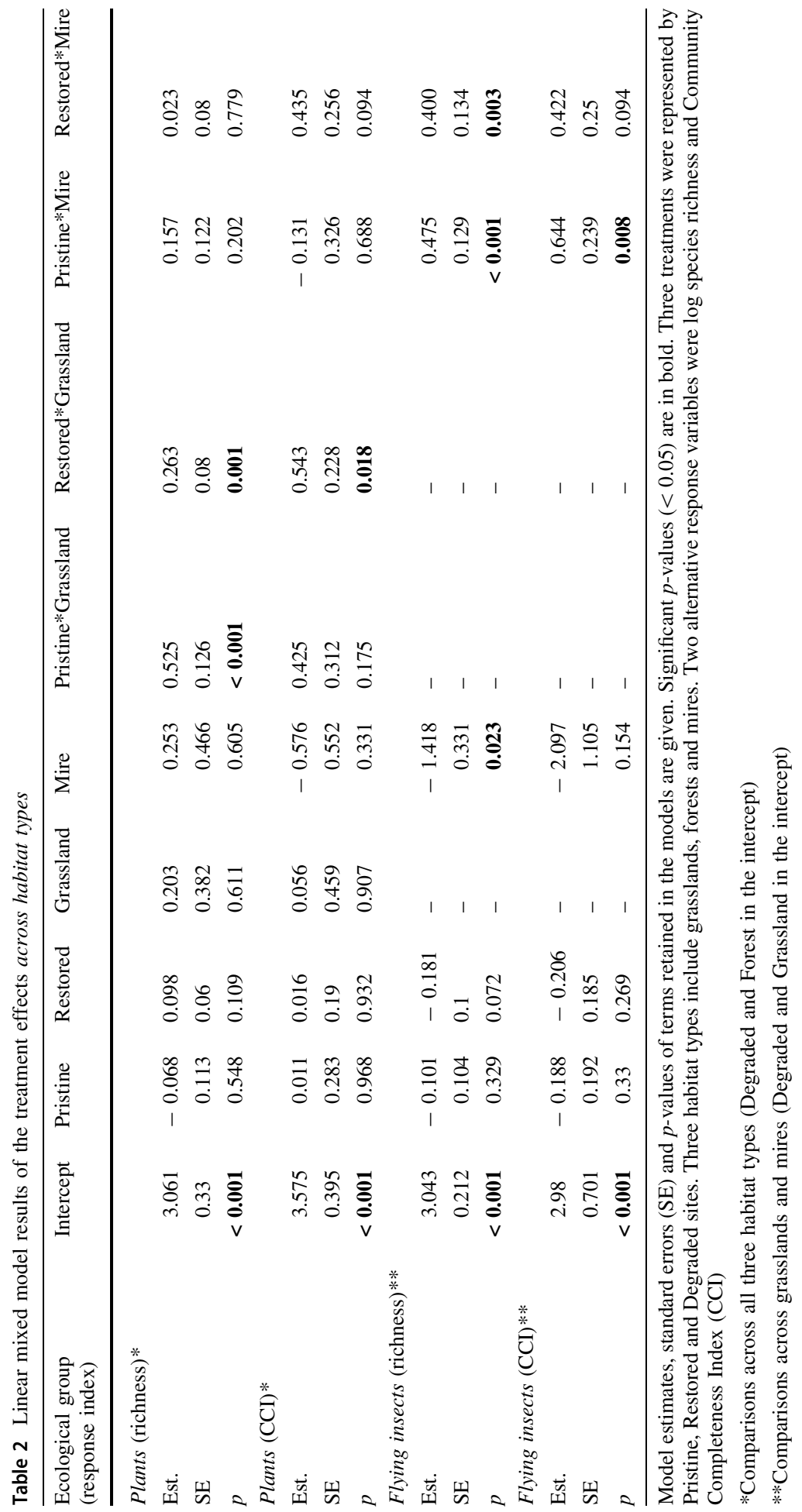



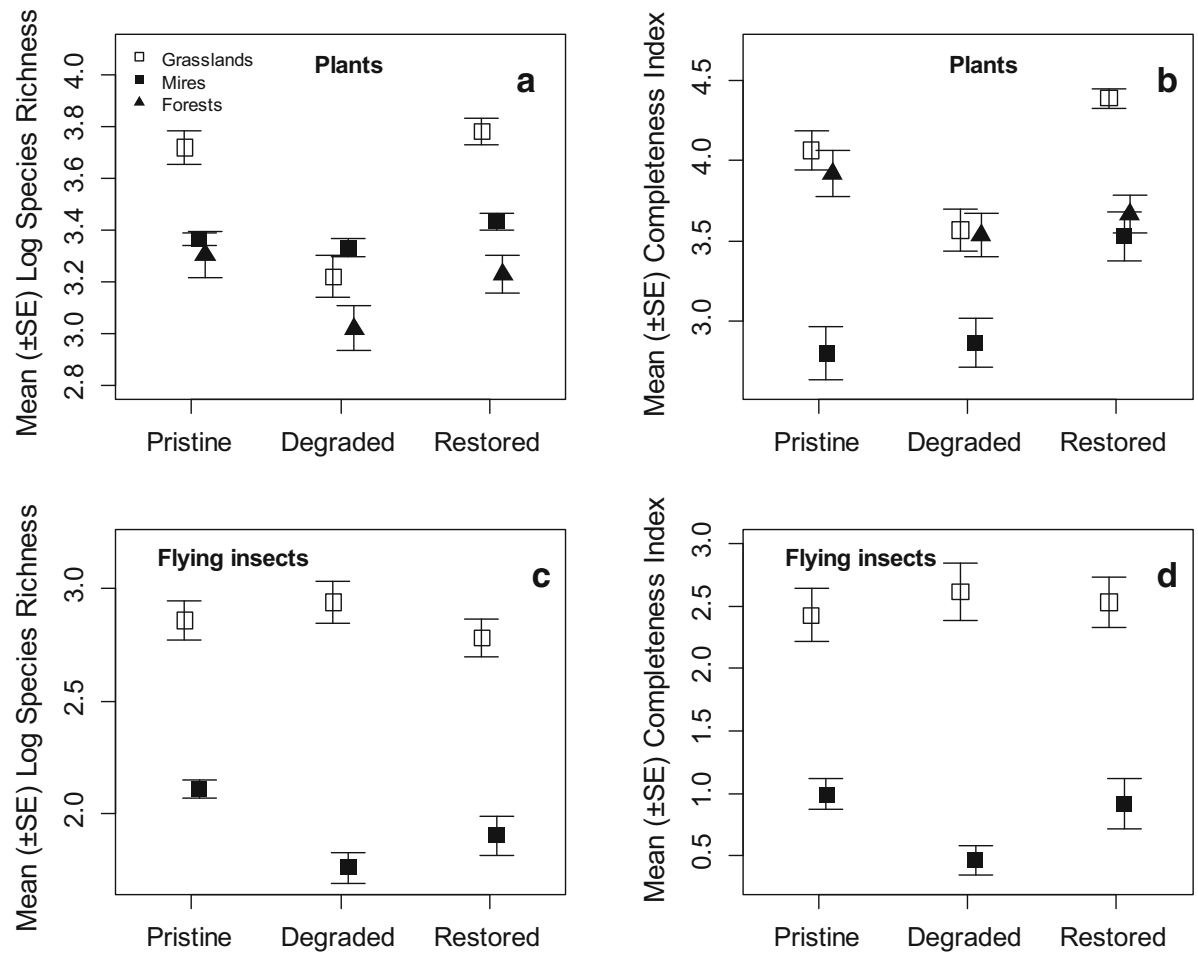

Fig. 2 Treatment effect comparisons across three habitat types and across grasslands and mires for plants (a, b) and for flying insects (c, d). Community comparisons were performed on log species richness (a, c) and community completeness index (b, d). Means and standard errors of both metrics are provided. Higher or lower CCI values indicate that, respectively, more or less species from habitat-specific species pool is realized within a site

richness demonstrated significant Pristine*Plants and Restored*Plants interactions (Table 3; Fig. 3c). However, overall species richness in restored grasslands were significantly lower. Grassland plant community completeness was highest for restored sites (significant interaction Restored*Plants), followed by pristine sites (significant interaction Pristine*Plants) (Table 2; Fig. 3d).

\section{Time since restoration effect on species richness and community completeness}

The analyses on overall time since restoration effect (16 datasets, Table 1) revealed a positive effect of time since restoration on community completeness (est. $=0.017$, $\mathrm{p}=0.031$, Fig. 4a), as well as on species richness (est. $=0.016, \mathrm{p}=0.001$, Fig. 4b). Thus, generally, restored communities become more species rich and more complete (gain more species from available species pool) with increasing time since restoration. Unexpectedly, this does not depend on ecological group nor habitat type, as the analyses of time since restoration effect on ecological groups within habitats and on habitats within ecological groups did not provide significant interactions (time since restoration*ecological group and time since restoration*habitat type, respectively). 


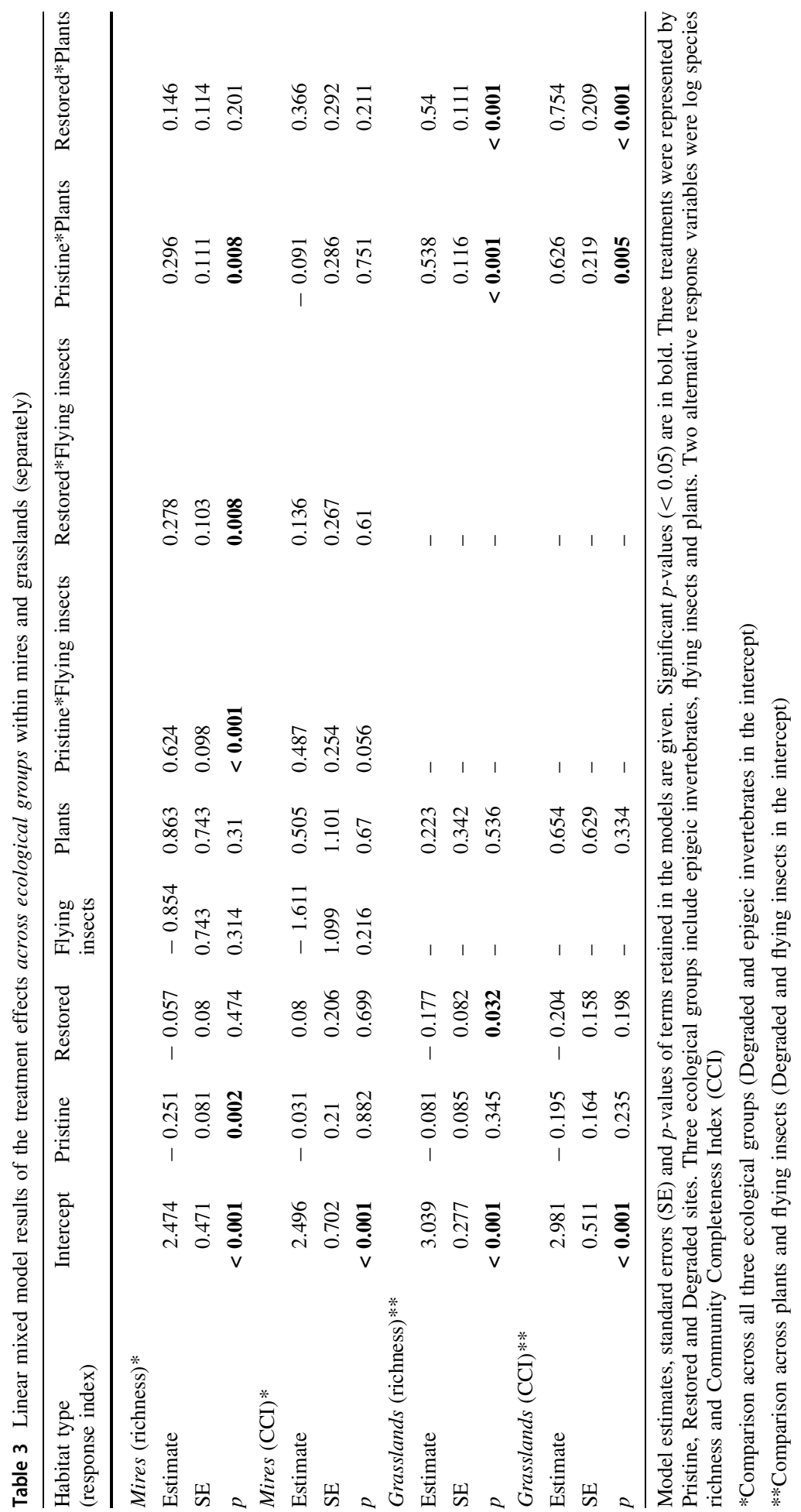



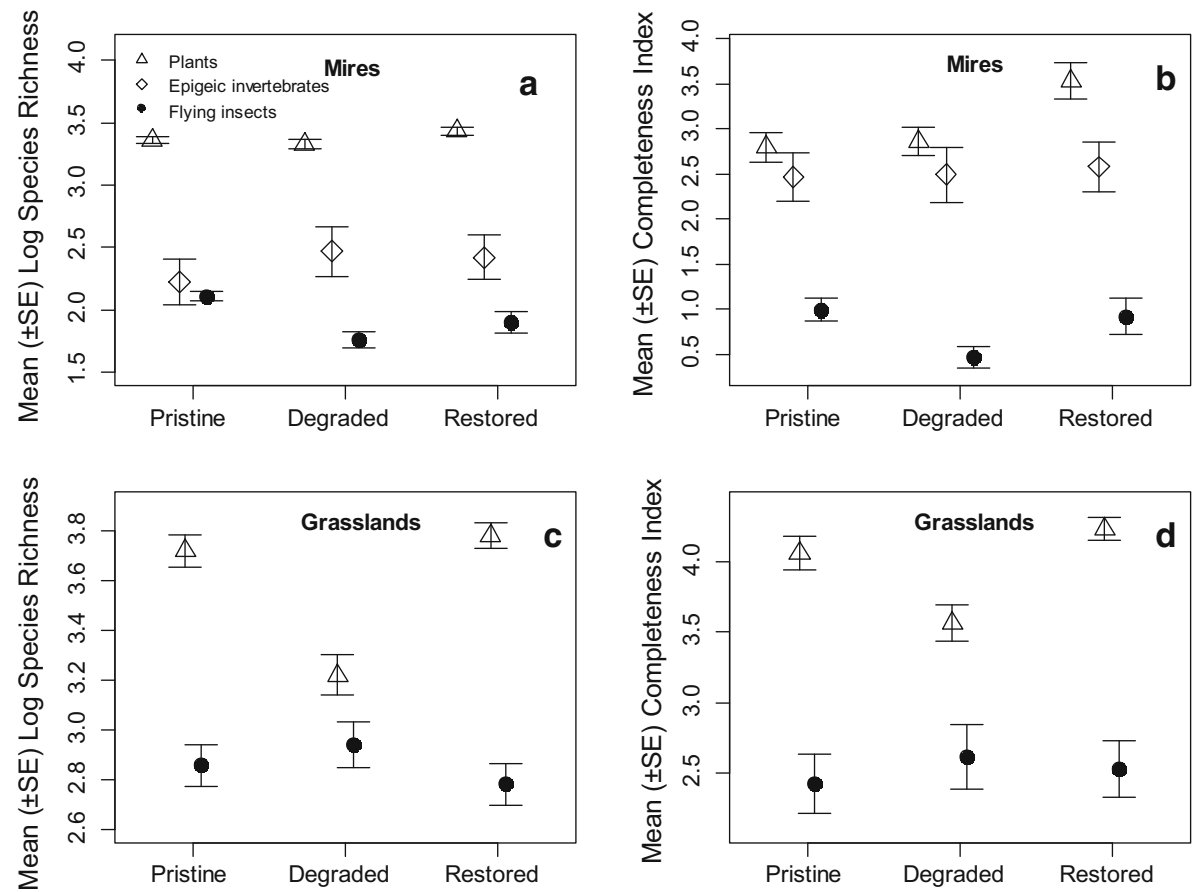

Fig. 3 Treatment effect comparisons across three ecological groups in mires (a, b) and across plants and flying insects in grasslands (c, d). Community comparisons were performed on log species richness (a, c) and community completeness index $(\mathbf{b}, \mathbf{d})$. Means and standard errors of both metrics are provided. Higher or lower CCI values indicate that, respectively, more or less species from habitat-specific species pool is realized within a site

\section{Discussion}

\section{The applicability of Community Completeness Index (CCI) in evaluating success of restoration actions}

Assessment of restoration success is a key subject in restoration ecology (Wortley et al. 2013; Prach et al. 2019), which requires clearly stated and justified goals (Gann et al. 2019; Prach et al. 2019). As such, restoration targets should include measurable indicators which contain mechanistic relationships to larger ecosystem structure and processes (Prach et al. 2019). Our multiple-study comparisons revealed that community completeness could be highly relevant in formulating goals of restoration projects, as well as it could serve as useful indicator while evaluating their success. We demonstrated that CCI could be used in making comparisons of restoration treatments across ecological groups (plants, epigeic invertebrates and flying insects) and across habitats (grasslands, mires and forests).

When comparing analyses with CCI and traditional species richness, there were many similarities. This is expected since local richness is the product of species pool size and community completeness. However, some results were significant only for richness, but not for CCI. These differences likely originate from variation in the species pool. For example, species richness might increase, but completeness remains the same if there are also more species in the dark diversity of specific habitat. In our study, species pool 

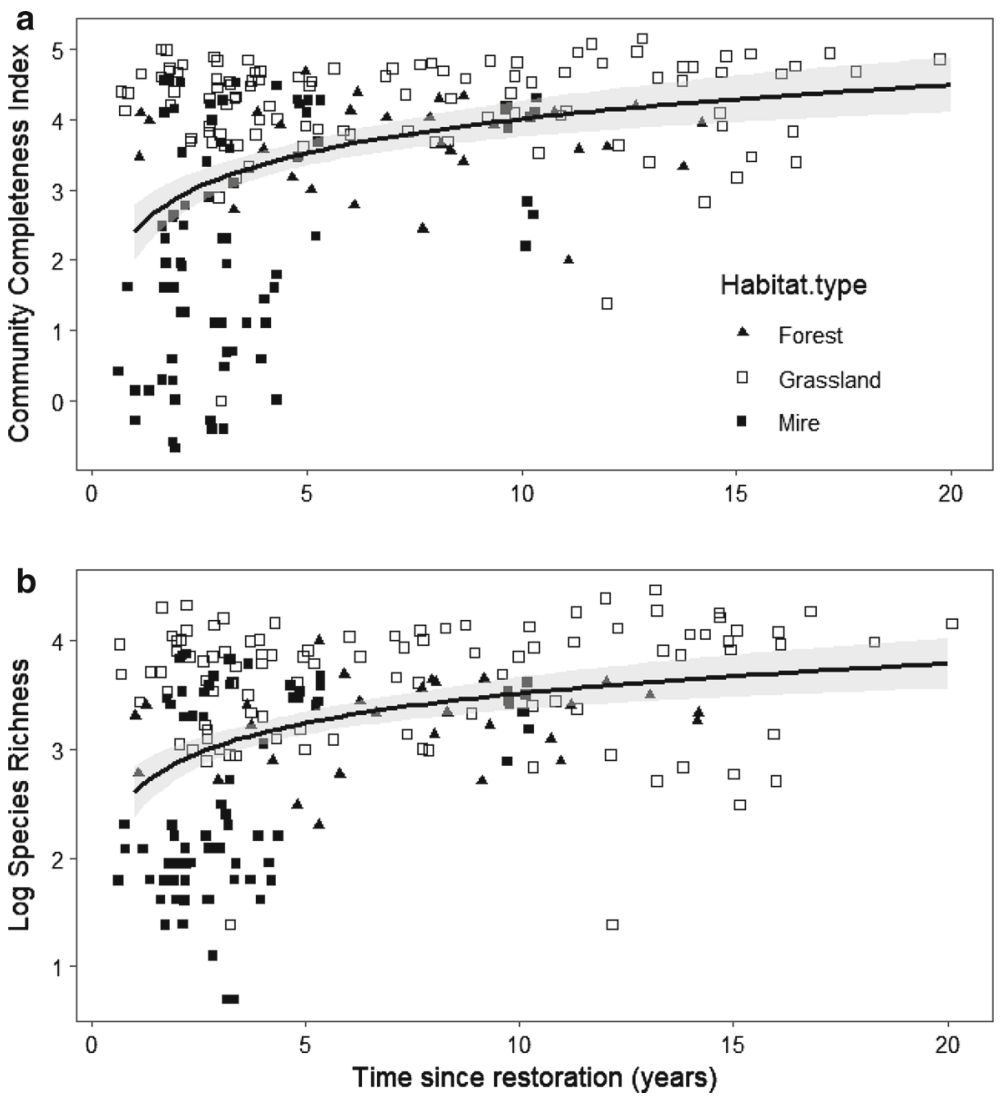

Fig. 4 Positive relationships between Community Completeness Index (a), log species richness (b) and time since restoration (in years). Regression lines and SE are provided. Different symbols represent separate restored sites from three habitat types: forests (triangle), grasslands (open square) and mires (black square)

variation effect seem to be especially associated with flying insect communities in restored mires. Many significant results were found for species richness, but not for CCI in across habitat type analyses for flying insects and in across ecological group analyses in mires. Likely, conditions in restored mire sites have changed so much for flying insects that species pools are different from pristine, indicating high specialisation of pristine mire insects and preference for stable habitat conditions. In contrast, the results which were evident both for richness and CCI seem to be more associated with plants in restored and pristine grasslands. These indicate directly the effect of local site-level process (restoration), as species pool effect was filtered out. Grassland plant communities seem to be improved by the restoration, as they prefer continuous disturbance. Finally, none of the site-level effects were completely masked by the species pool variation, as no results were statistically significant for CCI only.

CCI based restoration targets depend on the chosen principles of species pool and observed/dark diversity estimations. Here we used species presence-absence data from all sites (pristine, restored, degraded) within a study system to define estimates for CCI. In this case, any changes in CCI show if available species generally are being gained or lost due to restoration and, importantly, still allow across-taxa comparisons. However, this approach 
does not give information on whether restored habitats are approaching a specific target community, for example a historic or pristine state, as has traditionally been the main purpose of restoration actions (Jackson and Hobbs 2009). If the pristine state is a specific target, it would be more relevant to calculate CCI from species co-occurrence patterns in the pristine sites only or from other way defined habitat specific species pool of the region. However, it is increasingly recognized that in the era of rapid human-caused environmental changes, finding a suitable reference sites could be difficult or impossible because habitat degradation can be so widespread that none of the desired habitats exist (Murphy 2018; Prach et al. 2019) and ecosystems are changing continuously due to anthropogenic disturbances. As a result of these changes, restored ecosystems can turn into some alternative stable states with novel mixtures of species, thus resulting in hybrid or novel ecosystems (Hobbs et al. 2009). While evaluating restoration success, comparisons of restoration interventions against the counterfactual, rather than comparing against some fixed state, should be preferred (Corlett 2016). However, if the dynamic nature of ecosystems is considered while evaluating restoration success, then it appears problematic to define the desired restoration target. For example, which species should be considered as part of novel or hybrid ecosystem species pool and thus used in its CCI calculations? Clearly, actual species preferences to co-exist within whole study system should be used in such cases.

Despite differences in gaining estimates for CCI, a clear restoration goal could be to encourage all habitat-specific species available from the regional species pool to disperse and remain in the communities changed by restoration actions (= achieve higher CCI due to restoration). As such, CCI creates a link with mechanisms of larger processes: it reflects if suitable (or desirable) and available (from the regional pool) species are re-colonizing restored sites. Finally, as demonstrated in the current study, CCI allows comparisons across ecological group and across habitat types in accordance with restoration actions. Such comparisons are highly useful in both large and small-scale restoration projects. When entire landscapes are restored, then across-habitat comparisons would reveal if separate elements of the landscape are equally successfully restored. Similarly, when single habitat is restored, then across ecological group comparisons reveal if different elements of the whole ecosystem are being restored (Pärtel et al. 2013). In case some landscape or ecosystem elements are less successfully restored, the respective adaptive management techniques addressing specific elements could be applied.

Even though dark diversity and community completeness serve as promising tools in restoration ecology, they are relatively novel concepts (Pärtel et al. 2011) and thus their methodology is still under development (Brown et al. 2019; Carmona et al. 2019). For CCI estimations all species present within site must be recorded, or at least the possible bias of non-detected species should be the same throughout the study system. Thus, such bias is likely avoided when CCI is used for across habitat comparisons. However, it could be more difficult to avoid sampling bias in across ecological group comparisons. Differences in detectability and mobility between taxa can result in higher estimated completeness e.g. in plants which are sessile, and highly mobile animal (e.g., flying insect) communities. Also, flying insects might use several habitats during their life cycle (e.g., for feeding and nesting, Potts et al. 2005; Öckinger et al. 2018), thus the observed community composition is more likely to be just a snapshot of particular moment. However, at least bias in species detectability could be reduced by using environmental DNA as species detection method (see e.g. Boussarie et al. 2018). 


\section{Positive restoration effects on CCl: different ecological groups and ecosystem types, main restricting factors}

Restoration actions had a clear positive overall effect on completeness of communities, as CCI increased with the time since restoration. Furthermore, somewhat surprisingly, grassland plant communities had higher CCI in restored than in pristine sites. This could be linked with preference for disturbance of plant species in such habitats. In contrast, flying insect greatest completeness was associated with pristine mires, thus indicating their preference for very stable conditions. Likely, high CCI in restored sites indicates the dynamic nature of ecosystems, as our calculations of community completeness do not rely purely on species pools from reference sites, but instead consider general species cooccurrence patterns. As such, it is possible that hybrid ecosystems with mixed species pools (characteristic to both degraded and pristine state) were created by restoration actions (at least for plants in grasslands). Under this scenario, even after long time CCI should remain high for restored communities. Alternatively, it could be that poor competitor species with good dispersal abilities (r-strategists) arrived first to the restored sites (e.g., Woodcock et al. 2012), which temporally results in communities with high CCI values. However, in this case, K-strategists should outcompete r-strategists with time and the restored communities should become more similar in terms of their completeness values with those of pristine sites.

Indeed, post-restoration community completeness should depend on both spatial and temporal constraints, e.g., site connectivity, species dispersal abilities and the time since restoration, as these are among the most important factors for re-establishment after restoration (Jones et al. 2018; Rotchés-Ribalta et al. 2018). Species with poor dispersal abilities are also known to be part of dark diversity more often (Riibak et al. 2015; Moeslund et al. 2017; Miličić et al. 2020). In our study, across-habitat comparisons of plant communities indicated that regularly but with low intensity disturbed, and thus dominated by better dispersing species, communities (grasslands) became more "complete" faster than communities rarely but severely (forests) or almost never (mires) disturbed. However, across ecological group comparison clearly indicated that plant communities respond faster to restoration than better dispersing invertebrates (significantly positive restored*plants interaction in grasslands). Although this result could be linked to dispersal abilities (as plants are sessile, they need to respond immediately to environmental changes in a site), but more likely this is an indication of invertebrate dependency on plants. First autotrophs (lower trophic level in a foodweb) should establish after restoration, while heterotrophs (= higher trophic level) can respond only after changes in lower trophic level (e.g., Henson et al. 2009). This is also supported by the fact that greater CCI of flying insect communities was associated with pristine mires (i.e., with very stable conditions). Furthermore, fast plant response could be a result of seed bank effect: many plants could be present in degraded sites in dormant seed bank or as small remnant populations (Eriksson 1996; Kalamees et al. 2012; Vandvik et al. 2016), thus allowing plants to establish immediately after restoration. In contrast, invertebrates need to recolonize restored sites from nearby source populations (Öckinger et al. 2018). 


\section{Conclusions}

Our study revealed that CCI derived from species co-occurrences could be used in evaluating restoration success if its target is to increase the number of ecologically suitable species present in the habitat-specific species pool, in the restored sites. In such case, CCI would indicate if restoration overall increases diversity and would also allow direct comparisons across separate communities. The usefulness of CCI estimated from species co-occurrences is especially clear when reference sites are not available, for example, when restoration actions result in hybrid or novel ecosystems. However, this method is more limited when the purpose of restoration is to get back to some desired "pristine" state. Here estimates for CCI (habitat-specific species pool, dark/observed diversities) from co-occurrences must be derived by only using reference sites. In practice this means that higher number of pristine sites should be sampled in order to derive reliable estimates.

Acknowledgements Vitas Marozas, Liisa Maanavilja, Eeva-Stiina Tuittila, Juha Pöyry, Juha Pykälä, Tuomo Takala, Emelie Walden, Regina Lindborg, Julien Piqueray, Tuomas Haapalehto, Janne S. Kotiaho kindly provided the data for our analyses. NN was funded by The Carl Tryggers Foundation (contract CTS 18:826). EÖ received funding from the Swedish Environment Protection Agency (contract 802-0091-17). MP was supported by the Estonian Research Council (PRG609), and the European Regional Development Fund (Centre of Excellence EcolChange).

Authors' contributions NN, EÖ and MP developed the ideas and designed methodology; NN collected, compiled and analyzed the data, as well as wrote the first draft of the manuscript. All authors contributed to the manuscript and gave final approval for publication.

Funding Open access funding provided by Swedish University of Agricultural Sciences.

Data Accessibility All the data used in the current analyses were derived from previously published papers.

\section{Compliance with ethical standards}

Conflict of interest The authors declare that they have no conflict of interest.

Open Access This article is licensed under a Creative Commons Attribution 4.0 International License, which permits use, sharing, adaptation, distribution and reproduction in any medium or format, as long as you give appropriate credit to the original author(s) and the source, provide a link to the Creative Commons licence, and indicate if changes were made. The images or other third party material in this article are included in the article's Creative Commons licence, unless indicated otherwise in a credit line to the material. If material is not included in the article's Creative Commons licence and your intended use is not permitted by statutory regulation or exceeds the permitted use, you will need to obtain permission directly from the copyright holder. To view a copy of this licence, visit http://creativecommons.org/licenses/by/4.0/.

\section{References}

Betts MG, Wolf C, Pfeifer M, Banks-Leite C, Arroyo-Rodríguez V, Ribeiro DB, Barlow J, Eigenbrod F, Faria D, Fletcher RJ, Hadley AS, Hawes JE, Holt RD, Klingbeil B, Kormann U, Lens L, Levi T, Medina-Rangel GF, Melles SL, Mezger D, Morante-Filho JC, Orme CDL, Peres CA, Phalan BT, Pidgeon A, Possingham H, Ripple WJ, Slade EM, Somarriba E, Tobias JA, Tylianakis JM, UrbinaCardona JN, Valente JJ, Watling JI, Wells K, Wearn OR, Wood E, Young R, Ewers RM (2019) Extinction filters mediate the global effects of habitat fragmentation on animals. Science 366:1236-1239

Boussarie G, Bakker J, Wangensteen OS, Mariani S, Bonnin L, Juhel J-B, Kiszka JJ, Kulbicki M, Manel S, Robbins WD, Vigliola L, Mouillot D (2018) Environmental DNA illuminates the dark diversity of sharks. Sci Adv 4:eaap9661 
Brown JJ, Mennicken S, Massante JC, Dijoux S, Telea A, Benedek AM, Götzenberger L, Májeková M, Lepš J, Šmilauer P, Hrček J, de Bello F (2019) A novel method to predict dark diversity using unconstrained ordination analysis. J Veg Sci 30:610-619

Carmona CP, Szava-Kovats R, Pärtel M (2019) Estimating probabilistic dark diversity based on the hypergeometric distribution. bioRxiv, 636753

Christie AP, Amano T, Martin PA, Shackelford GE, Simmons BI, Sutherland WJ (2019) Simple study designs in ecology produce inaccurate estimates of biodiversity responses. J Appl Ecol 56:2742-2754

Corlett RT (2016) Restoration, reintroduction, and rewilding in a changing world. Trends Ecol Evol 31:453-462

Ellis EC (2018) Anthropocene: a very short introduction. Oxford University Press, Oxford

Eriksson O (1996) Regional dynamics of plants: a review of evidence for remnant, source-sink and metapopulations. Oikos 77:248-258

Gann GD, McDonald T, Walder B, Aronson J, Nelson CR, Jonson J, Hallett JG, Eisenberg C, Guariguata MR, Liu J, Hua F, Echeverría C, Gonzales E, Shaw N, Decleer K, Dixon KW (2019) International principles and standards for the practice of ecological restoration, Second edition. Restor Ecol 27:S1S46

Haapalehto T, Juutinen R, Kareksela S, Kuitunen M, Tahvanainen T, Vuori H, Kotiaho JS (2017) Recovery of plant communities after ecological restoration of forestry-drained peatlands. Ecol Evol 7:7848-7858

Henson KSE, Craze PG, Memmott J (2009) The restoration of parasites, parasitoids, and pathogens to heathland communities. Ecology 90:1840-1851

Hobbs RJ, Higgs E, Harris JA (2009) Novel ecosystems: implications for conservation and restoration. Trends Ecol Evol 24:599-605

Jackson ST, Hobbs RJ (2009) Ecological restoration in the light of ecological history. Science 325:567-569

Jones HP, Jones PC, Barbier EB, Blackburn RC, Benayas R, Holl JM, McCrackin KD, Meli M, Montoya P, D. \& Mateos DM (2018) Restoration and repair of Earth's damaged ecosystems. Proceedings. Biological Sciences, 285

Kalamees R, Püssa K, Zobel K, Zobel M (2012) Restoration potential of the persistent soil seed bank in successional calcareous (alvar) grasslands in Estonia. Appl Veg Sci 15:208-218

Kärvemo S, Björkman C, Johansson T, Weslien J, Hjältén J (2017) Forest restoration as a double-edged sword: the conflict between biodiversity conservation and pest control. J Appl Ecol 54:1658-1668

Lewis SL, Maslin MA (2015) Defining the Anthropocene. Nature 519:171-180

Lewis RJ, Szava-Kovats R, Pärtel M (2016) Estimating dark diversity and species pools: an empirical assessment of two methods. Methods Ecol Evol 7:104-113

Lindeman RL (1942) The trophic-dynamic aspect of ecology. Ecology 23:399-417

Maanavilja L, Aapala K, Haapalehto T, Kotiaho JS, Tuittila E-S (2014) Impact of drainage and hydrological restoration on vegetation structure in boreal spruce swamp forests. For Ecol Manag 330:115-125

Marozas V, Racinskas J, Bartkevicius E (2007) Dynamics of ground vegetation after surface fires in hemiboreal Pinus sylvestris forests. For Ecol Manag 250:47-55

McAlpine C, Catterall CP, Nally RM, Lindenmayer D, Reid JL, Holl KD, Bennett AF, Runting RK, Wilson K, Hobbs RJ, Seabrook L, Cunningham S, Moilanen A, Maron M, Shoo L, Lunt I, Vesk P, Rumpff L, Martin TG, Thomson J, Possingham H (2016) Integrating plant- and animal-based perspectives for more effective restoration of biodiversity. Front Ecol Environ 14:37-45

Miličić M, Popov S, Vujić A, Ivošević B, Cardoso P (2020) Come to the dark side! The role of functional traits in shaping dark diversity patterns of south-eastern European hoverflies. Ecol Entomol 45:232-242

Moeslund JE, Brunbjerg AK, Clausen KK, Dalby L, Fløjgaard C, Juel A, Lenoir J (2017) Using dark diversity and plant characteristics to guide conservation and restoration. J Appl Ecol 54:1730-1741

Murphy SD (2018) Restoration Ecology's Silver Jubilee: meeting the challenges and forging opportunities. Restor Ecol 26:3-4

Noreika N, Kotiaho JS, Penttinen J, Punttila P, Vuori A, Pajunen T, Autio O, Loukola OJ, Kotze DJ (2015) Rapid recovery of invertebrate communities after ecological restoration of boreal mires. Restor Ecol 23:566-579

Noreika N, Kotze DJ, Loukola OJ, Sormunen N, Vuori A, Päivinen J, Penttinen J, Punttila P, Kotiaho JS (2016) Specialist butterflies benefit most from the ecological restoration of mires. Biol Conserv 196:103-114

Öckinger E, Eriksson AK, Smith HG (2006) Effects of grassland abandonment, restoration and management on butterflies and vascular plants. Biol Conserv 133:291-300

Öckinger E, Winsa M, Roberts SPM, Bommarco R (2018) Mobility and resource use influence the occurrence of pollinating insects in restored seminatural grassland fragments. Restor Ecol 26:873-881 
Palmer MA, Ambrose RF, Poff NL (1997) Ecological theory and community restoration ecology. Restor Ecol 5:291-300

Pärtel M, Szava-Kovats R, Zobel M (2011) Dark diversity: shedding light on absent species. Trends Ecol Evol 26:124-128

Pärtel M, Szava-Kovats R, Zobel M (2013) Community completeness: linking local and dark diversity within the species pool concept. Folia Geobot 48:307-317

Pinheiro J, Bates D, DebRoy S, Sarkar D \& R Core Team. (2020) Nlme: linear and nonlinear mixed effects models

Piqueray J, Bottin G, Delescaille L-M, Bisteau E, Colinet G, Mahy G (2011) Rapid restoration of a speciesrich ecosystem assessed from soil and vegetation indicators: the case of calcareous grasslands restored from forest stands. Ecol Ind 11:724-733

Potts SG, Vulliamy B, Roberts S, O'Toole C, Dafni A, Ne'eman G, Willmer P (2005) Role of nesting resources in organising diverse bee communities in a Mediterranean landscape. Ecol Entomol 30:78-85

Pöyry J, Lindgren S, Salminen J, Kuussaari M (2004) Restoration of butterfly and moth communities in semi-natural grasslands by cattle grazing. Ecol Appl 14:1656-1670

Prach K, Durigan G, Fennessy S, Overbeck GE, Torezan JM, Murphy SD (2019) A primer on choosing goals and indicators to evaluate ecological restoration success. Restor Ecol 27:917-923

Punttila P, Autio O, Kotiaho JS, Kotze DJ, Loukola OJ, Noreika N, Vuori A, Vepsäläinen K (2016) The effects of drainage and restoration of pine mires on habitat structure, vegetation and ants. Silva Fennica 50:article id 1462

Pykälä J (2005) Plant species responses to cattle grazing in mesic semi-natural grassland. Agr Ecosyst Environ 108:109-117

R Core Team (2019) R: A Language and Environment for Statistical Computing. Vienna, Austria. https:// www.r-project.org/

Riibak K, Reitalu T, Tamme R, Helm A, Gerhold P, Znamenskiy S, Bengtsson K, Rosén E, Prentice HC, Pärtel M (2015) Dark diversity in dry calcareous grasslands is determined by dispersal ability and stress-tolerance. Ecography 38:713-721

Rotchés-Ribalta R, Winsa M, Roberts SPM, Öckinger E (2018) Associations between plant and pollinator communities under grassland restoration respond mainly to landscape connectivity. J Appl Ecol 55:2822-2833

Suding KN (2011) Toward an era of restoration in ecology: successes, failures, and opportunities ahead. Annu Rev Ecol Evol Syst 42:465-487

Takala T, Tahvanainen T, Kouki J (2012) Can re-establishment of cattle grazing restore bryophyte diversity in abandoned mesic semi-natural grasslands? Biodivers Conserv 21:981-992

Török P, Helm A (2017) Ecological theory provides strong support for habitat restoration. Biol Conserv 206:85-91

Vandvik V, Klanderud K, Meineri E, Måren IE, Töpper J (2016) Seed banks are biodiversity reservoirs: species-area relationships above versus below ground. Oikos 125:218-228

Waldén E, Lindborg R (2016) Long term positive effect of grassland restoration on plant diversity—success or not? PLoS ONE 11:e0155836

Winsa M, Öckinger E, Bommarco R, Lindborg R, Roberts SPM, Wärnsberg J, Bartomeus I (2017) Sustained functional composition of pollinators in restored pastures despite slow functional restoration of plants. Ecol Evol 7:3836-3846

Woodcock BA, Bullock JM, Mortimer SR, Brereton T, Redhead JW, Thomas JA, Pywell RF (2012) Identifying time lags in the restoration of grassland butterfly communities: A multi-site assessment. Biol Conserv 155:50-58

Wortley L, Hero J-M, Howes M (2013) Evaluating Ecological Restoration Success: A Review of the Literature. Restor Ecol 21:537-543

Zobel M (2016) The species pool concept as a framework for studying patterns of plant diversity. J Veg Sci 27:8-18

Publisher's Note Springer Nature remains neutral with regard to jurisdictional claims in published maps and institutional affiliations. 


\section{Affiliations}

\section{Norbertas Noreika $^{1,2}$ (1) $\cdot$ Meelis Pärtel $^{3} \cdot$ Erik Öckinger $^{1}$}

$\triangle$ Norbertas Noreika

norbertas.noreika@gmail.com

1 Department of Ecology, Swedish University of Agricultural Sciences, PO Box 7044, 75007 Uppsala, Sweden

2 Chair of Plant Health, Institute of Agricultural and Environmental Sciences, Estonian University of Life Sciences, Kreutzwaldi 5, 51014 Tartu, Estonia

3 Institute of Ecology and Earth Sciences, University of Tartu, Lai 40, 51005 Tartu, Estonia 